\title{
ALTERATIONS IN MUSCLE TENSION WITHOUT SIMILAR CHANGES IN ELECTRICAL ACTIVITY IN PATIENTS WITH MYASTHENIA GRAVIS ${ }^{1}$
}

\author{
By STELLA Y. BOTELHO \\ (From the Department of Physiology and Pharmacology, Graduate School of Medicine, Uni- \\ versity of Pennsylvania, Philadelphia, Pa.)
}

(Submitted for publication February 25, 1955 ; accepted May 25, 1955)

Certain discrepancies between the electrical and mechanical activity of skeletal muscle in patients with myasthenia gravis have been pointed out previously (1). However, simultaneously recorded action potentials and tension have been reported only once in patients with this disorder (2) and no quantitative analysis has been made of the relationship between electrical and mechanical activity of skeletal muscle of patients with myasthenia gravis. The results of the present study of simultaneously recorded electrical and mechanical activity of intact muscle in six patients with myasthenia gravis indicate that changes in tension reflect more accurately the degree of muscle weakness than do changes in electrical activity and changes in contractile ability of the muscle can occur, both before and after neostigmine, without similar changes detectable in neuromuscular transmission.

\section{APPARATUS AND METHODS}

The method and apparatus have been described in detail elsewhere (3). In brief, we recorded simultaneously action potentials from and isometric tension developed by the adductor pollicis muscle, which was induced to contract by supramaximal, percutaneous stimulation of the ulnar nerve at the elbow. We are cognizant of the fact that movements of the thumb are complex and therefore we might not be recording mechanical and electrical activity from the same group of muscles. However, an electrode on the belly of the adductor pollicis was certainly picking up electrical activity of muscles which are innervated by the ulnar nerve. When supramaximal stimuli were used potentials of duplicate single twitches, successive twitches with $3 / \mathrm{sec}$. and successive responses with $30 / \mathrm{sec}$. did not vary more than 10 per cent in 48 normal subjects. The same was true of tension. When the ulnar nerve is stimulated at the elbow, the hypothenar,

1 Aided by a research grant (USPHS B-128) from the National Institute of Neurological Disease and Blindness of the National Institutes of Health, U. S. Public Health Service. A portion of this paper was presented at the International Myasthenia Gravis Conference in Philadelphia, December 8, 1954. forearm flexor, interosseus and palmaris brevis contract. However, if ulnar deviation, wrist flexion and finger flexion are prevented, as they were in the present study, these muscles contribute very little to the tension developed by the adductor pollicis when it is initially stretched. In fact, when these other movements occur, the bar tends to be pushed up and the recorded tension is less. Any opposition of the thumb also tends to decrease tension since an oblique rather than perpendicular force is applied to the bar. In any case with supramaximal stimuli the tension developed by successive twitches or duplicate tetanus in 48 normal subjects did not vary more than 10 per cent. In this study, we have considered only changes greater than 10 per cent to be significant (three times standard deviation of the mean of individual differences).

The ulnar nerve was stimulated either with single twitches or at the rate of $3 / \mathrm{sec}$. for 2 seconds (at which rate there was no fusion of successive twitches), 2 minutes before and at intervals varying from 1 to $10 \mathrm{~min}$ utes after a tetanus produced by $30 / \mathrm{sec}$. stimulation for 1 second. Records were taken in six patients both when they were weak but not necessarily in a basal state (at least 3 to 4 hours after their usual oral dose of neostigmine, Table 1) and again when they felt stronger (20 to 30 minutes after intramuscular injection of 1.5 mgm. neostigmine with $0.6 \mathrm{mgm}$. atropine). In addition conduction velocities along the ulnar nerve were determined in three additional patients by measuring the distance between two points of stimulation (elbow and wrist) and the difference in latencies between stimulus and artefact when the nerve was stimulated at these two points. Before tetanus the ulnar nerve was stimulated successively at elbow and wrist with single shocks to determine the difference in latency. The differences in latency of the first and fifth responses were determined when tetanus was obtained with $30 / \mathrm{sec}$. for 1 second by stimulation at both wrist and elbow. By this technique one determines the conduction velocity of the fastest fibers as they conduct only from elbow to wrist.

We are fully aware of the fact that different muscle groups are variously affected in patients with myasthenia gravis and that voluntary muscle contraction does not necessarily measure the same thing that is measured when one measures tension developed with supramaximal indirect stimulation. However, the patients in this study showed a decrease in ptosis and increased strength of adduction of the thumb (as judged by their ability to 
TABLE 1

Clinical data

\begin{tabular}{|c|c|c|c|c|c|c|}
\hline Patient & Sex & $\begin{array}{l}\text { Age } \\
\text { yrs. }\end{array}$ & $\begin{array}{c}\text { Age at } \\
\text { onset of } \\
\text { symptoms } \\
y r s .\end{array}$ & $\begin{array}{c}\text { Daily oral } \\
\text { dose of } \\
\text { neostigmine } \\
\text { mgm. }\end{array}$ & $\begin{array}{c}\text { Interval } \\
\text { between } \\
\text { last dose of } \\
\text { neostigmine } \\
\text { and study } \\
\text { hrs. }\end{array}$ & $\begin{array}{l}\text { Calibration } \\
\text { of EMG } \\
\mathrm{mV} / \mathrm{mm} .\end{array}$ \\
\hline D. D. & F & 18 & 18 & 0 & $24^{*}$ & .3 \\
\hline B. G. & $\mathrm{F}$ & 3 & 3 & 0 & $24^{*}$ & 4 \\
\hline $\mathrm{Na}-1$ & F & 37 & 21 & 0 & $24^{*}$ & .5 \\
\hline $\mathrm{Na}-2$ & $\mathrm{~F}$ & 44 & 21 & $30 \mathrm{q} 4 \mathrm{~h}$. & $4-5$ & .3 \\
\hline L. P. & M & 32 & 25 & 0 & $24^{*}$ & .3 \\
\hline E. R. & F & 24 & 21 & $7.5 \mathrm{q} 3 \mathrm{~h}$. & $3-4$ & .3 \\
\hline M. W. & $\mathrm{F}$ & 19 & 13 & $15 \mathrm{q} 4 \mathrm{~h}$. & $8-9$ & .3 \\
\hline M. S. W. & $F$ & 20 & 14 & $15 \mathrm{q} 4 \mathrm{~h}$. & $7-8$ & .4 \\
\hline M. A. & F & 28 & 22 & $15 \mathrm{q} 4 \mathrm{~h}$. & $5-6$ & .4 \\
\hline
\end{tabular}

* 1.5 mgm. neostigmine with $0.6 \mathrm{mgm}$. atropine had been given intramuscularly for diagnostic purposes 24 hours before the studies were done.

hold a sheet of paper between the thumb and first metacarpal by adduction of the thumb), 30 minutes after intramuscular neostigmine. Other pertinent clinical data are given in Table 1 .

Although it is known that tension and amplitude of action potentials vary with age and initial muscle length, insufficient data are available from normal human adductor pollicis muscle to permit comparison with patients with myasthenia gravis. For this reason absolute values for amplitude of muscle action potentials are not given but they can be obtained from the calibration factors in Table 1 since the amplification system was linear and the sensitivity remained the same throughout any one study.

\section{RESULTS}

3/sec. stimulation (Table 2): Before neostigmine, there was a decrease in the tension developed by successive twitches in each patient; the tension developed by the fifth twitch was, on the average, 70 per cent that developed by the first twitch. Such a decrease in the tension of suc-

IAPR5 28 Simultaneove tension and action potentiale developed by the actuctor pollieis brevis miscle with 3/sec. stimulation of the vinar nerve at the elbow. In this and subsequent tables, changes lese than to the lot and 5 th atimulue.

\begin{tabular}{|c|c|c|c|c|c|c|c|c|}
\hline \multicolumn{5}{|c|}{ Promenostigaino } & \multicolumn{4}{|c|}{ Postmpoostiguino } \\
\hline \multirow[t]{2}{*}{ Patsente } & \multicolumn{2}{|c|}{$\begin{array}{c}\text { Tonotion } \\
\text { Ban. }\end{array}$} & \multicolumn{2}{|c|}{$\begin{array}{c}\text { Aetion Pot. } \\
\text { Amplitudo } \\
\text {. }\end{array}$} & \multicolumn{2}{|c|}{$\begin{array}{c}\text { Tenason } \\
T_{0}\end{array}$} & \multicolumn{2}{|c|}{$\begin{array}{l}\text { Aetion Pot. } \\
\text { Anplitude }\end{array}$} \\
\hline & 1 & 5 & 1 & 5 & 1 & 5 & 1 & 5 \\
\hline E.P. & 580 & 450 & 19 & 17.5 & 550 & 470 & 25 & 26 \\
\hline LoP. & 680 & 430 & 31 & 22 & 770 & 680 & 32 & 31 \\
\hline LW. & 760 & 640 & 32 & 32 & 775 & 650 & 33 & 32.5 \\
\hline thos.w. & 510 & 240 & 36 & 35 & 470 & 390 & 34 & 34 \\
\hline poen & 633 & 440 & 29.5 & 26.6 & 641 & 548 & 31 & 30.9 \\
\hline
\end{tabular}

cessive twitches at $3 / \mathrm{sec}$. does not occur in normal subjects. There were no consistent changes in amplitudes of the accompanying action potentials, i.e., there was no change in amplitude in E. R., M. W. (Figure 1) and M. S. W., and a moderate decrease in L. P.; thus per cent decrease in tension did not parallel per cent decrease in amplitude of the action potential. After neostigmine there was no significant change in the first twitch tension in E. R., M. W. (Figure 1) and M. S. W. and a slight increase in tension developed by the first twitch in L. P. Again there was no correlation between electrical and mechanical activity, e.g., there was an increase in amplitude of the first action potential unaccompanied by an increase in tension in E. R. whereas in L. P. there was an increase in tension developed by the first twitch unaccompanied by any significant change in the action potential. The lower action potential in $\mathrm{E}$. R. was not the result of a change in amplification since the calibration factor remained the same throughout this, as well as all other studies. After neostigmine, the fifth twitch developed greater tension than before in E. R., L. P. and M. S. W. so that, on the average, the fifth twitch tension was 85 per cent that of the first. There was good correlation between electrical and mechanical activity in E. R., L. P. and M. W.; however, in M. S. W., despite the greater tension developed by the fifth twitch after neostigmine, there was no increase in amplitude of the accompanying action potential. There were no significant changes in either the delay (interval between beginning of stimulus artifact and beginning of the 
action potential) or latent period (interval between beginning of action potential and beginning of the rise in tension) of successive twitches at $3 / \mathrm{sec}$. either before or after neostigmine.

30/sec. stimulation (Table 3): Before neostigmine. The electromyographic picture of a decrement of successive action potentials described by Harvey and Masland in 1941 (1) occurred in three patients (E. R., Figure 2, L. P. and M. S. W.) but there was no significant change in the amplitude of successive potentials in the other patient (M. W.). The conduction velocities of the ulnar nerve were normal both before and dur-

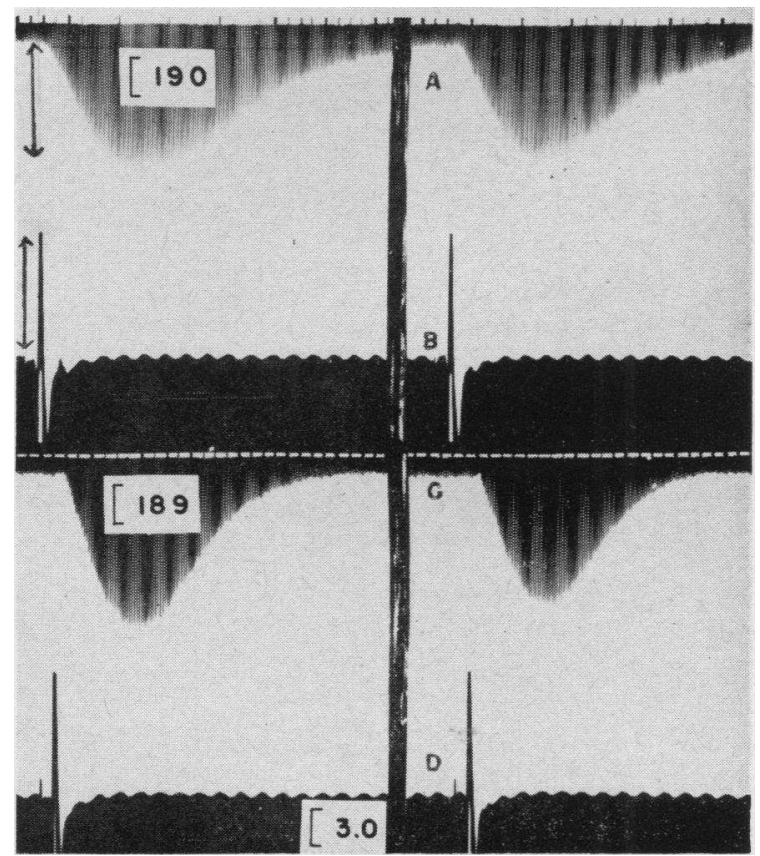

Fig. 1. Patient M. W. First (on Reader's Left) and Fifth (on Reader's Right) Mechanical (A AND C) and Electrical (B and D) Responses of the AdDuctor Pollicis to 3/Sec. Stimulation of the Ulnar Nerve 8 to 9 Hours after 15 mgm. Oral Neostigmine (A AND B) AND 20 Min. AFTER 1.5 MGM. Intramuscular Neostigmine (C AND D)

In this and all subsequent figures, lines $\mathrm{A}$ and $\mathrm{C}$ record tension, maximum developed tension being measured as indicated by the upper arrow; lines B and D record electrical activity, the amplitude of the negative phase being measured as indicated by the lower arrow; the small upward deflection preceding the negative phase of the action potential when present is the stimulus artifact; and each of the widest time markers indicates 0.03 sec. In this figure calibration of tension is in terms of $\mathrm{gm}$./extremes of the bracket and of electrical activity in terms of $\mathrm{mV} /$ extremes of the bracket.
TABS 3, 30/8ec. stimulation before and 20-30 inutes arter intramuscular noosti gine.

\begin{tabular}{|c|c|c|c|c|c|c|}
\hline \multirow{3}{*}{ Patient } & \multicolumn{3}{|c|}{ Pro-Neostigaine } & \multicolumn{3}{|c|}{ Post-100 stifatne } \\
\hline & $\begin{array}{c}\text { Tonotion } \\
\text { gino }\end{array}$ & Act1 & $\begin{array}{l}\text { Pot. } \\
\text { tude } \\
\text { - }\end{array}$ & Tension & Aetion & $\begin{array}{l}\text { Pot. } \\
\text { Itwodo } \\
\text { a. }\end{array}$ \\
\hline & & $I$ & 5 & & 1 & 5 \\
\hline E.R. & 3000 & 22 & 15 & 3150 & 26 & 30 \\
\hline L.P. & 3500 & 30 & 16 & 3200 & 29 & 25 \\
\hline พ.ซ. & 2950 & 33 & 32 & 3950 & 29 & 26 \\
\hline Y.S.T. & 3460 & 35 & 20 & 4200 & 43 & 37 \\
\hline Yean & 3228 & 30 & 20.9 & 3625 & 31.8 & 29.5 \\
\hline
\end{tabular}

ing the tetanus at a time when the action potentials had decreased in three other patients (Table 4). After neostigmine, there was an increase in tetanus tension in two patients (M. W. and M. S. W.) and no change in tetanus tension in the other two patients (E. R., Figure 2, and L. P.). Thus only in M. S. W. was there a correlation between the mechanical and electrical activity since only here was the increased tension accompanied by an increase in amplitude of the first potential and a decrease in decrement of successive potentials. In the other three patients there was no correlation between electrical and mechanical activity.

Post-tetanic potentiation of twitch tension: $\mathrm{Be}$ fore neostigmine (Table 5): Single twitch tension, as judged by the first twitch with $3 / \mathrm{sec}$. stimulation, was greater after tetanus than the corresponding twitch before tetanus. As in normal subjects (3), this potentiation of twitch tension was unaccompanied by a change in the action potential. In two other myasthenia gravis patients (N. A.-2 and M. A., Table 6) we found that al-

TABR 48 Conduction velocity of ulnar nerve ( $\left.\boldsymbol{w} / \mathrm{sec}_{0}\right), 1$ and J0 aro the responses to the int and 30th otimull: Tetarus produced by $25 / \mathrm{sec}$. stimulation for 1.2 sec.

\begin{tabular}{|c|c|c|c|c|}
\hline \multirow[t]{3}{*}{ Patient } & \multirow{3}{*}{$\frac{\text { Before Tetanue }}{\text { C.Y. }}$} & \multicolumn{3}{|c|}{ During Tetarus } \\
\hline & & \multirow[t]{2}{*}{ C. $\nabla_{\text {. }}$} & \multicolumn{2}{|c|}{$\begin{array}{l}\text { Act. Pot, } \\
\text { ampl. (t) }\end{array}$} \\
\hline & & & 1 & 30 \\
\hline$N_{0} A_{0}-1$ & 55.2 & 55.0 & 16 & 20 \\
\hline$B_{0} G_{0}$ & 75.0 & 74.2 & 29 & 25 \\
\hline D.D. & 50.7 & 51.1 & 19 & 9 \\
\hline
\end{tabular}




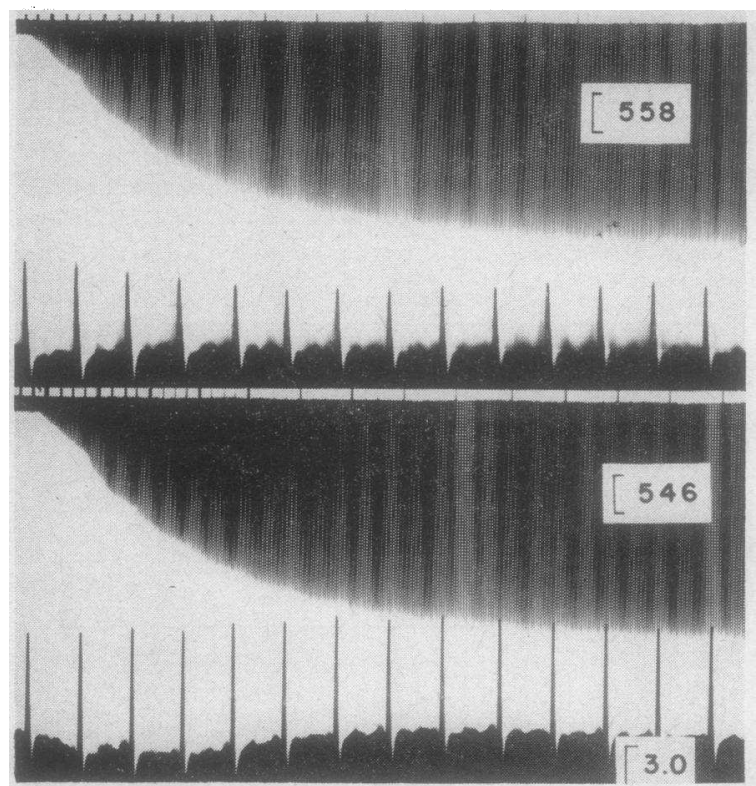

Fig. 2. Patient E. R. Simultaneols Mechanical and Electrical Responses of the Adductor Pollicis to 30/Sec. Stimulation of the Ulnar Nerve 3 to 4 Hours after 7.5 mgm. Oral Neostigmine (Upper Two Lines) and 20 to 30 min. After 1.5 mgM. Intramescular Neostigmine (Lower 2 Lines)

In this figure, calibration of tension is in terms of $\mathrm{gm}$./extremes of the bracket and of electrical activity in terms of $\mathrm{mV}$ /extremes of the bracket.

though the twitch tension was potentiated at $1 \mathrm{~min}$. it was not potentiated $2 \mathrm{~min}$. after the tetanus; this is unlike normal human subjects, in whom posttetanic potentiation of twitch tension lasts at least 10 min. (3). After tetanus, there was a progressive decrement in tension of successive twitches with $3 / \mathrm{sec}$. stimulation in all four myasthenia gravis patients; again this is unlike normal human subjects, in whom the tension of successive

TASLE 5: 3/sec. stimulation after tetanns before and 20-30 mimutos ofter intramuscular neostignine.

\begin{tabular}{|c|c|c|c|c|c|c|c|c|}
\hline \multicolumn{5}{|c|}{ Pre-neostigmingo } & \multicolumn{4}{|c|}{ Post-neostignine } \\
\hline \multirow[t]{2}{*}{ Pationts } & \multicolumn{2}{|c|}{$\begin{array}{c}\text { Tension } \\
\text {. }\end{array}$} & \multicolumn{2}{|c|}{$\begin{array}{c}\text { Action Pot. } \\
\text { Appli tud } \\
\end{array}$} & \multicolumn{2}{|c|}{$\begin{array}{c}\text { Tension } \\
\text { gan. }\end{array}$} & \multicolumn{2}{|c|}{$\begin{array}{c}\text { Action Pot. } \\
\text { Amplil tude } \\
\text { m. }\end{array}$} \\
\hline & 1 & 5 & 1 & 5 & 1 & 5 & 1 & 5 \\
\hline E.R. & 800 & 675 & 17.5 & 15 & 770 & 695 & 22.5 & 16.5 \\
\hline L.P. & 800 & 230 & 33 & 23 & 2100 & 800 & 31 & 26 \\
\hline Y.ซ. & 2025 & 940 & 32.5 & 32 & 1150 & 975 & 32 & 32 \\
\hline M.S.w. & 1200 & 190 & 35 & 27 & 1400 & 500 & 34 & 33 \\
\hline nave & 956 & 509 & 29.5 & 21.8 & 2105 & 743 & 29.9 & 26.9 \\
\hline
\end{tabular}

TABLS 68 Single twitches before and after tetamas,

\begin{tabular}{|c|c|c|c|c|c|c|}
\hline \multirow[b]{3}{*}{ Patient } & \multicolumn{2}{|c|}{ Pre-Tetanus } & \multicolumn{4}{|c|}{ Post-Tetarus } \\
\hline & \multirow[b]{2}{*}{$\begin{array}{c}\text { Tension } \\
\text { gm. }^{-}\end{array}$} & \multirow[b]{2}{*}{$\begin{array}{l}\text { Act. } \\
\text { Pot. } \\
\text { (nim) }\end{array}$} & \multicolumn{2}{|c|}{1 minute } & \multicolumn{2}{|c|}{2 nimites } \\
\hline & & & $\begin{array}{c}\text { Tension } \\
\text {. }\end{array}$ & $\begin{array}{l}\text { Act. } \\
\text { Pot. } \\
\text { (mm) }\end{array}$ & $\begin{array}{c}\text { Tension } \\
\text { gun. }\end{array}$ & $\begin{array}{l}\text { Act. } \\
\text { Pot. } \\
\text { (min) }\end{array}$ \\
\hline $\mathrm{N} \cdot \mathrm{A} \cdot-2$ & 250 & 26 & 310 & 25 & 250 & 25.5 \\
\hline Mol. & 860 & 35 & 990 & 36 & 840 & 35 \\
\hline
\end{tabular}

twitches after tetanus at this stimulation rate is maintained at the potentiated single twitch level (4). This decrement in successive twitch tensions was greater after tetanus in patients $\mathrm{L}$. P. and M. S. W. and about the same in patients E. R.

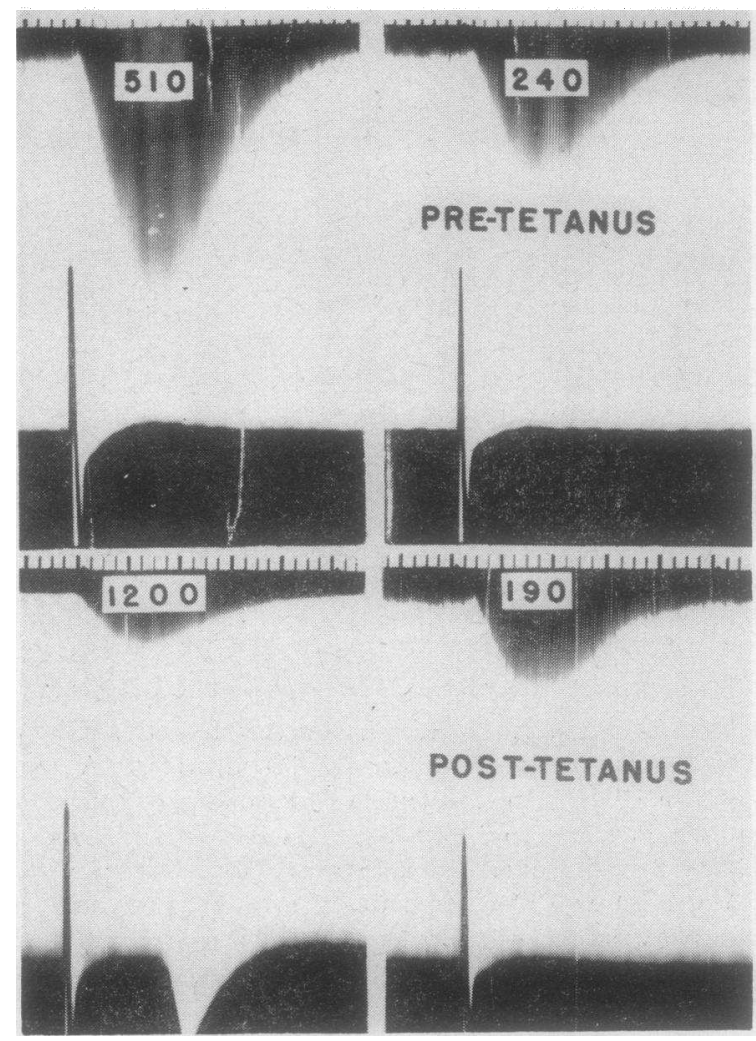

Fig. 3. Patient M. S. W. First (on Reader's Left) and Fifth (on Reader's Right) Mechanical and Electrical Responses of Adductor Pollicis Muscle to 3/Sec. Stimulation of the Ulnar Nerve Before and After Tetanus of 30/Sec. for 1 Sec. 7 to 8 Hours After 15 mgm. Oral Neostigmine

In this figure the number on the tension line indicates the maximum tension developed by the muscle in grams. 
and M. W. when compared to the pre-tetanus decrement. There were no consistent changes in the action potential after tetanus, e.g., the action potential decrement increased after tetanus in E. R. whereas the tension decrement did not and the action potentials did not decline in M. W. but the tension did. In L. P. and M. S. W. (Figure 3 ) there was an increase in decrement of action potentials as well as in decrement of tension after tetanus. After neostigmine, there was 1) an increase in the potentiation of the initial twitch tension in three patients without an alteration in the action potential and 2) either a decrease or increase in decrement of successive twitch tensions with $3 / \mathrm{sec}$. stimulation with no consistent change in the action potentials.

\section{DISCUSSION}

We interpret the results of the present study of the simultaneous electrical and mechanical activity of the adductor pollicis muscle during activity induced by supramaximal stimulation of the ulnar nerve in patients with myasthenia gravis as follows : Tension changes, especially at slow rates ( $3 / \mathrm{sec}$.) which are much more comfortable than tetanus rates (faster than $25 / \mathrm{sec}$.) are more accurate guides to the degree of muscle weakness than the electrical changes. The data lend further support to previous observations of the diffculties encountered when using the action potential pattern alone to diagnose myasthenia gravis (5).

Studies of either mechanical or electrical activity but not of both simultaneously have led to apparently conflicting conclusions. Thus Lindsley (6) reported a decrease in single twitch tension which increased with neostigmine but Pritchard (7) did not find that the single twitch tension of one myasthenia gravis patient was less than normal and Harvey and Masland (1) were unable to detect any decrease in the action potential of single induced twitches in patients with myasthenia gravis. All authors (7-9) agree that slow (about $3 / \mathrm{sec}$.) repetitive contraction produces a successive decrease in tension in patients with myasthenia gravis. However, it has been demonstrated that some patients with this disorder do not have a decrement in amplitude of successive twitch potentials with induced $3 / \mathrm{sec}$. stimulation (5). Furthermore, various workers $(6,7,9)$ have been unable to demonstrate any change in tetanus tension until stimulation rates exceeding $80 / \mathrm{sec}$. were used. But some workers have found that patients with myasthenia gravis show a progressive decrease in amplitude of successive potentials during tetanus with stimulation rates less than 40/ sec. (1) and other workers have shown that although some patients with myasthenia gravis do show this electromyographic picture, others do not (5). These discrepancies cannot be explained entirely by the suggestion that various technical differences were present such as, 1) submaximal stimuli were used in some studies, 2) the interval between single stimuli and duration of tetanus varied from study to study, and 3) the severity of the disease varied from study to study. We believe that other explanations must be sought and suggest the following: 1) Myasthenia gravis, at least in some muscles of some patients, is associated with notable muscle weakness which is not accompanied by any discernible degree of neuromuscular transmission block. The findings of the present study which support this are: (a) successive twitch tensions at $3 / \mathrm{sec}$. stimulation decreased significantly without any significant change in the action potentials (E. R., M. W., and M. S. W.), and (b) after an induced tetanus, successive twitch tensions at $3 / \mathrm{sec}$. are initially potentiated but not sustained at the potentiated level; this abnormal finding is not accompanied by a consistent alteration in the action potential (E. R. and M. W.) ; 2) It is possible that posttetanic potentiation of twitch tension, which we have shown to occur in the present study, sustains the tension during the tetanus despite a decrease in the action potentials. Brown and Burns (10) have suggested that when mammalian muscle is fatigued, there is alternation of motor unit activity during the tetanus; this explains the successive decline of the action potentials. The inactive fibers are now in the post-tetanus state even though the tetanus is continuing so that when they again contract they can contribute a greater increment of tension than they could have, had they been active throughout the tetanus. Since there is alternation of activity and inactivity of the various fibers, the tension during tetanus is sustained at the initial level because of this post-tetanic potentiation. Post-tetanic potentiation of twitch tension unassociated with facilitation of the action 
potential has been shown to occur in normal human muscle and the factors which may be responsible for this phenomenon are discussed elsewhere (3).

Since the changes in muscle tension which occurred after neostigmine were not necessarily the result of changes in neuromuscular block as judged by the associated action potentials, we believe that neostigmine can have a direct effect upon the contractile ability of muscle apart from or in addition to its effect upon neuromuscular transmission. Although their data do not necessarily indicate that neostigmine has an effect on the contractile mechanism, Riker and Wescoe (11) have at least shown that neostigmine can stimulate denervated mammalian skeletal muscle. In the present study we have not excluded the possibility that the contraction was altered after neostigmine as a result of changes in the circulation to the muscle.

Although it has been shown that neostigmine administered intraarterially produces repetitive firing of normal human muscle in response to a single supramaximal stimulus (12), we were unable to demonstrate this in the present study, probably because we were using surface electrodes. It is therefore possible that repetitive firing of individual muscle fibers was present and could account for an increase in tension without altering the summed potential. If this were so, the decrease in successive twitch tensions without a decrease in action potential with $3 / \mathrm{sec}$. stimulation might result from the fact that the small amounts of circulating neostigmine present from 3 to 9 hours after oral neostigmine caused repetitive firing when the muscle was stimulated through its nerve; this repetitive response would decrease with each such successive stimulus and therefore the tension of each successive twitch would decrease. If this were so, we would expect that increasing the amount of neostigmine by intramuscular injection would cause an increase in repetitive discharge of the muscle. We would then expect an increase in initial twitch tension as well as an increase in the tension of successive twitches but this occurred in only one of the four patients.

It has been shown that evoked action potentials recorded from various parts of a muscle have different forms and this might account for the differences in electrical and mechanical activity which were found in this study. It is quite true that different shaped action potentials are recorded from different parts of large muscles when surface electrodes are used (13) and from different parts of small muscles when needle electrodes are used (14). However, we do not believe this to be an important factor in the present study since the surface electrodes we used practically covered the entire belly of the adductor pollicis muscle.

It is possible that the amplitude of the action potentials may not truly reflect changes in the number of active fibers since more synchronous firing of fewer fibers could produce a potential of greater amplitude; however, in this case there should then be an alteration in the area or duration of the potential (15). Since there were no changes in potential duration or area, we believe that variations in potential amplitude did reflect variations in the number of active fibers and thus alterations in the degree of neuromuscular block. The findings of increased, decreased, or unaltered muscle tension in the absence of similar changes in neuromuscular block indicated that neostigmine can have a direct effect upon skeletal muscle of patients with myasthenia gravis. We believe that the efficacy of neostigmine must, at least in part, be the result of such a direct action.

We cannot overlook the possibility that myasthenia gravis as diagnosed by clinical signs and symptoms and frequently confirmed by the administration of neostigmine or curare (which has also been shown to have a direct effect both on mammalian [16] and human [4] skeletal muscle) may include not only patients who are weak because of a neuromuscular transmission defect but also patients who are weak because of the inability of the muscle to contract. It is apparent that the muscle as well as neuromuscular junction must be studied in order to elucidate the pathophysiology of myasthenia gravis and to obtain more effective therapeutic agents.

\section{SUMMARY}

The results of the present study show that changes in the degree of mechanical activity can occur without similar electrical changes in the adductor pollicis muscle of patients with myasthenia gravis upon supra-maximal stimulation of the ulnar nerve with single twitches, $3 / \mathrm{sec}$. stimulation 
and $30 / \mathrm{sec}$. stimulation both before and after intramuscular neostigmine. The findings suggest 1) that changes in tension reflect more accurately the degree of muscle weakness than changes in electrical activity, 2) in some muscles of some myasthenia gravis patients the muscle weakness results from a defect in contractile ability apart from or in addition to a defect in neuromuscular transmission, 3) neostigmine is useful in some patients with myasthenia gravis because of its ability to alter the contractile processes of the muscle apart from or in addition to decreasing neuromuscular block and 4) the muscle must not be neglected in studies designed (a) to elucidate the pathophysiology of myasthenia gravis and (b) to obtain better therapeutic agents in this disorder.

\section{ACKNOWLEDGMENT}

The author wishes to thank Dr. George Gammon for the opportunity to study the majority of these patients and Dr. Julius $\mathrm{H}$. Comroe, Jr. for his valuable critique of the manuscript.

\section{REFERENCES}

1. Harvey, A. M., and Masland, R. L., The electromyogram in myasthenia gravis. Bull. Johns Hopkins Hosp., 1941, 69, 1.

2. Grob, D., and Harvey, A. M., Abnormalities in neuromuscular transmission with special reference to myasthenia gravis. Am. J. Med., 1953, 15, 695.

3. Botelho, S. Y., and Cander, L., Post-tetanic potentiation before and during ischemia in intact human skeletal muscle. J. Applied Physiol., 1953, 6, 221.

4. Botelho, S. Y., Simultaneous electrical and mechanical responses to indirect stimulation in curarized subjects. In preparation.

5. Botelho, S. Y., Deaterly, C. F., Austin, S., and Comroe, J. H., Jr., Evaluation of the electromyogram of patients with myasthenia gravis. Arch. Neurol. \& Psychiat., 1952, 67, 441.

6. Lindsley, D. B., Myographic and electromyographic studies of myasthenia gravis. Brain, 1935, 58, 470.

7. Pritchard, E. A. B., The occurrence of Wedensky inhibition in myasthenia gravis. Proceedings of the Physiological Society, February 18, 1933. J. Physiol., 1933, 78, 3P.

8. Jolly, F., Ueber myasthenia gravis pseudoparalytica. Part I., Berl. Klin. Wchnschr., 1895, 32, 1.

9. Odom, G., Russell, S. K., and McEachern, D., Studies of neuromuscular disorders: The myogram, blood cholinesterase and effect of prostigmine in myasthenia gravis and progressive muscle dystrophy. Brain, 1943, 66, 1.

10. Brown, G. L., and Burns, B. D., Fatigue and neuromuscular block in mammalian skeletal muscle. Proc. Roy. Soc., London, s.B., 1949, 136, 182.

11. Riker, W. F., Jr., and Wescoe, W. C., The direct action of prostigmine on skeletal muscle; its relationship to the choline esters. J. Pharmacol. \& Exper. Therap., 1946, 88, 58.

12. Harvey, A. M., Lilienthal, J. L., Jr., and Talbot, S. A., On the effects of the intra-arterial injection of acetylcholine and prostigmine in normal man. Bull. Johns Hopkins Hosp., 1941, 69, 529.

13. Hodes, R., Larrabee, M. G., and German, W., The human electromyogram in response to nerve stimulation and the conduction velocity of motor axons. Studies on normal and on injured peripheral nerves. Arch. Neurol. \& Psychiat., 1948, 60, 340.

14. Jarcho, L. W., Eyzaguirre, C., Berman, B., and Lilienthal, J. L., Jr., Spread of excitation in skeletal muscle: Some factors contributing to the form of the electromyogram. Am. J. Physiol., 1952, 168, 446.

15. Harvey, A. M., and Masland, R. L., A method for the study of neuromuscular transmission in human subjects. Bull. Johns Hopkins Hosp., 1941, $68,81$.

16. Bean, J. W., and Elwell, L. H., Influence of d-tubocurarine on contractile response of mammalian skeletal muscle in situ. Am. J. Physiol., 1951, 165, 716. 